\title{
Superficial self-diffusion coefficient in Ih-ICE
}

\author{
Carlos Leonardo Di Prinzio ${ }^{1,2 *}$, Damian Stoler ${ }^{1}$, Guillermo Aguirre \\ Varela $^{1,2}$, Esteban Druetta $^{1}$ \\ ${ }^{1}$ Facultad de Matemática, Astronomía, Física y Computación, Universidad Nacional de \\ Córdoba (FaMAF-UNC), Medina Allende y Haya de la Torre, Ciudad Universitaria, \\ Córdoba (5000), Córdoba, Argentina \\ ${ }^{2}$ Instituto de Física Enrique Gaviola (IFEG-CONICET) Medina Allende y Haya de la \\ Torre, Ciudad Universitaria. Córdoba (5000), Córdoba, Argentina
}

\begin{abstract}
The evolution of the grain boundary groove in a bicrystalline ice sample was studied in this work. The groove is formed by the intersection of the grain boundary with the free surface. The bicrystalline ice sample had an arbitrary misorientation and was immersed in ultra-pure silicone oil at $-5^{\circ} \mathrm{C}$ in order to avoid evaporation processes. Photographs of the groove were taken every 17 minutes for 100 hours with an optical microscope and the evolution of the groove was determined from these images. Through this study, it was possible to measure the coefficient of surface self-diffusion of the ice at $-5^{\circ} \mathrm{C}$.
\end{abstract}

Key words: grain boundary, surface self-diffusion, ice

DOI: $10.5817 / \mathrm{CPR} 2020-2-12$

\section{Introduction}

Human activities have already changed the chemical composition of the natural atmosphere even in the most remote regions of the world. The study of solid and accumulated precipitation in the polar ice caps over the last few hundred thousand years provides a unique tool to obtain information about the composition of the pre-industrial atmosphere and its natural variability in the past (Alley et al. 1993, Barrie 1986).

The ice in polar caps or glaciers has an hexagonal crystalline structure called Ih (ice hexagonal) and its surface structure depends on the crystalline orientation and thermodynamic variables such as temperature and pressure (Brumberg et al. 2017,
Wehinger et al. 2014, Fukazawa and Mae 2000).

The study of the surface properties of ice at temperatures near the melting point provides relevant information on transport processes of atmospheric pollutants that are of interest in atmospheric physics and glaciology (Dibb 1992, Dibb et al. 1992, Dibb and Whitlow 1996).

Dibb et al. (1992) found concentrations of ${ }^{7} \mathrm{Be},{ }^{210} \mathrm{~Pb}$ and major ions in aerosol and snow samples collected in GISP2 (Greenland Ice Sheet Project 2) in the summers of 1989 and 1990. Dibb and Whitlow (1996) also demonstrated the connection between air pollutants on snow and polar ice. Cli-

Received July 23, 2020, accepted December 29, 2020.

*Corresponding author: C. L. Di Prinzio < diprinzio@famaf.unc.edu.ar>

Acknowledgements: This work has been enabled thanks to the collaboration of José Barcelona and the financial support of SeCyT (UNC's Science and Technology Secretary). 
mate change and the increase in greenhouse gases can be studied with the composition of the air stored in polar ice bubbles for thousands of years (Alley et al. 2003). The bubbles are mostly located at the grain boundaries (GB) of the polar ice (Weiss et al. 2002, Durand et al. 2006, Fegyveresi et al. 2011, Azuma et. al. 2012, Faria et al. 2014). Liquid veins also form in the GB and triple grain bonds when they have a high concentration of impurities; and these can produce variations in the determination of the constituents of the past atmosphere (Rempel et al. 2001). The movement of contaminants, gases and impurities in bubbles or liquid veins involves transport mechanisms on the surface of the ice.

Surface self-diffusion (the transport of water molecules over the ice) is a phenomenon of interest that occurs on the ice surface, and which can be studied through the temporal evolution of the groove of the grain boundary (GB). The GB groove can be formed by mechanisms such as: evaporation-condensation, surface self-diffusion (Mullins 1957), volumetric diffusion or gaseous diffusion Mullins (1960).

Mullins (1957) studied the GB groove and evaporation-condensation and surface self-diffusion effects were considered. This method can be generally applied to many materials and, in this case, we applied it on pure ice. If the surface of ice in contact with a gaseous phase and the ice surface energy is considered isotropic, the groove shape has a characteristic shape only considering the surface self-diffusion (Fig. 1).

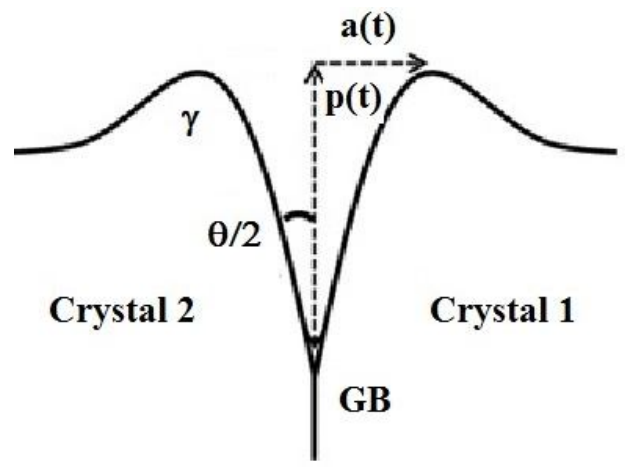

Fig. 1. Shape of the groove formed under surface self-diffusion mechanism (modified from Stoler et al. 2019).

By symmetry, the shape of the groove to the right and left of the GB is the same and both surfaces form an angle $\theta$. Mullins (1957) determined that the semi-width $a$ and the depth of the groove $p$ evolve as follows:

$$
\begin{array}{rr}
a(t)=2,3(B t)^{\frac{1}{4}} & \text { Eqn. } 1 \\
p(t)=0,967 m(B t)^{\frac{1}{4}} & \text { Eqn. } 2
\end{array}
$$

where $m$ is the tangent of the $\theta$ angle, $B$ is a parameter that has the following relation to the surface self-diffusion coefficient $D_{s}$ :

$$
B=\frac{D_{s} \gamma \Omega^{2} v}{(k T)}
$$

Eqn. 3

where $\Omega$ is the atomic volume, $\gamma$ is the surface energy per unit area, $v$ is the number of atoms per unit area, $k$ is Boltzman's constant and $T$ is the temperature in kelvin. 

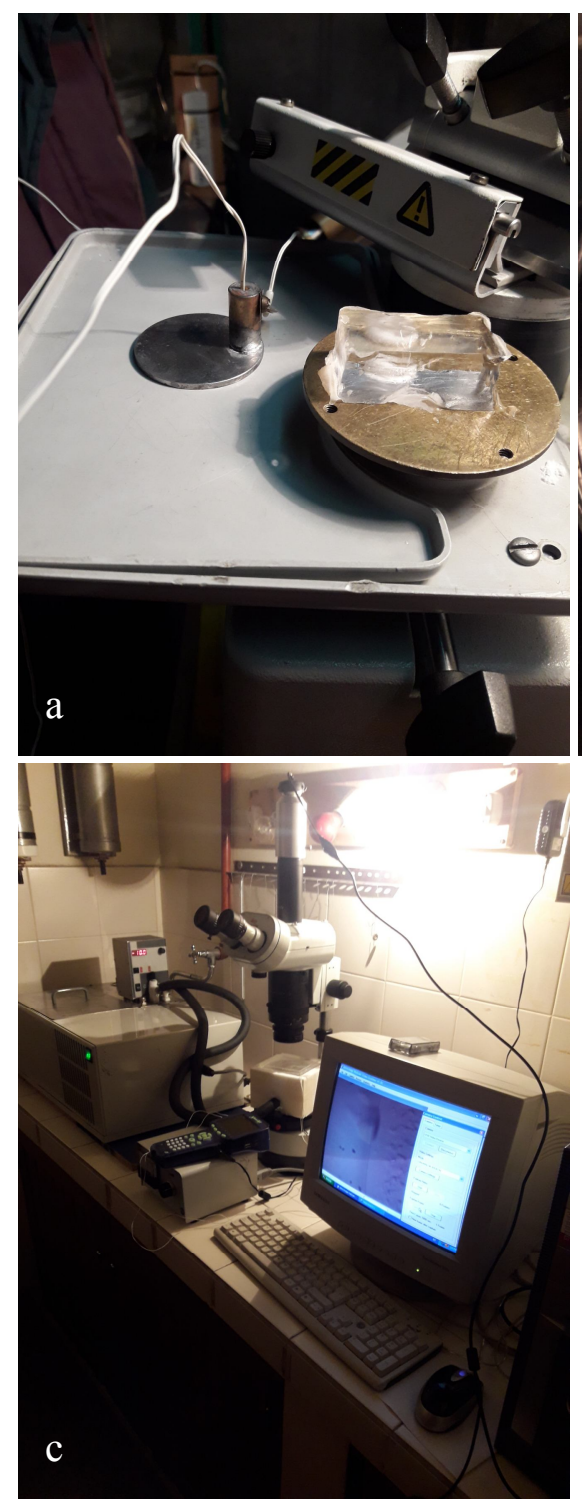

Recently, Style and Worster (2005) presented a quasi-liquid layer model to describe the surface of ice in contact with a gaseous phase, and proposed a new mass transport mechanism on the ice surface. The evolution of a BG groove is theoretically described in an environment with a high vapor pressure by an equation similar to equation (1) (Mullins 1957). However, they reported a different functional form

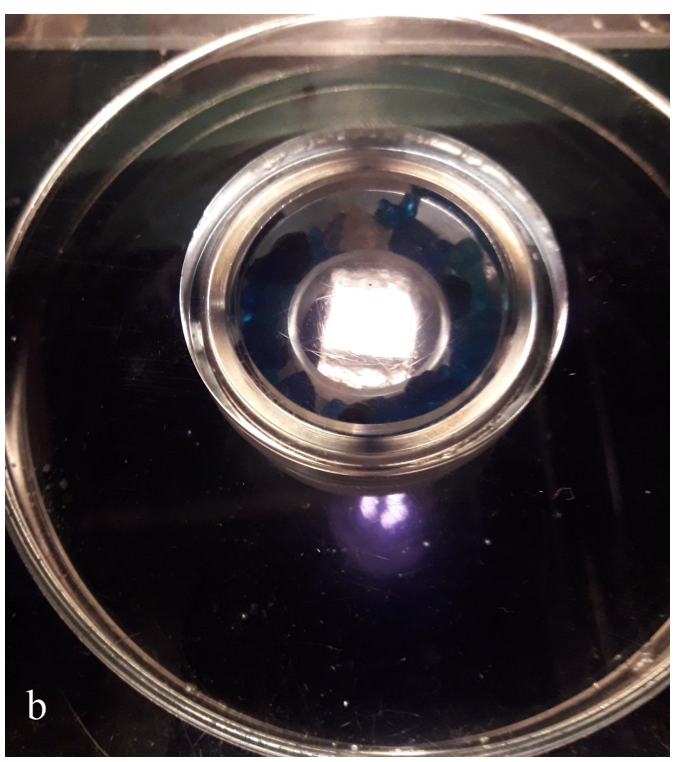

Fig. 2. a) Ice sample on the cold microtome; b) Ice sample immersed in silicon oil inside the hermetic cell; c) Experimental set-up (microscope with digital camera controlled by computer and cold cell thermostatically controlled by the circulating bath).

for the mass transport coefficient B, which depends on the melting temperature and other quantities such as a coefficient of viscosity. Although the model proposed by Style and Worster (2005) to describe the quasi-liquid layer is not restricted only to situations where the ice surface is in contact with a gaseous medium, they consider only the presence of air in their work. 
In this work, the evolution of the BG groove of an ice bicrystal covered with silicone oil is reported and the quasi-liquid

\section{Material and Methods}

Experiments were carried out in ice bicrystalline samples prepared according to the method proposed by Nasello et al. (2007). The surface sample was polished using a microtome LEICA ${ }^{\circledR}$ model: 1320 (Fig. 2a) and immediately immersed in a transparent acrylic cell with silicone oil. The cell was sealed to prevent evaporation or gaseous diffusion as shown in Fig. 2b.

The cell with the bicrystalline sample was placed in a temperature-controlled box, which was placed on a microscope stage. The box was arranged to keep the cell temperature at $-5^{\circ} \mathrm{C}$. For this purpose, ethylene glycol was pumped through the double wall of the box by Heto ${ }^{\circledR} 13$ DT-1 pump in Heto ${ }^{\circledR}$ CB-8-30E cooling system. The evolution of the groove was studied for 100 hours, taking photographs with a digital camera attached to the microscope (Leica M420 Macroscope Macro Zoom WILD 246634), and storing data/images automatically using an Astra Image webcam ${ }^{\circledR}$. Photographs of the groove were taken every $17 \mathrm{~min}$. layer model proposed by Style and Worster (2005) was applied.

Fig. 3a shows the GB groove after $50 \mathrm{~h}$. Using Image $\mathrm{B}$, the grey tone profile of the photo was plotted on the area shown. The result of image analysis is shown in Fig. 3b. The groove can be distinguished as the central peak. The half-width of the groove was identified with the half-width of that peak, that is, half the distance between the adjacent minima points to the central peak. Using a micrometric scale a pixel- $\mu \mathrm{m}$ conversion was made. This analysis was made for each photo obtained and the groove width temporal evolution was obtained.

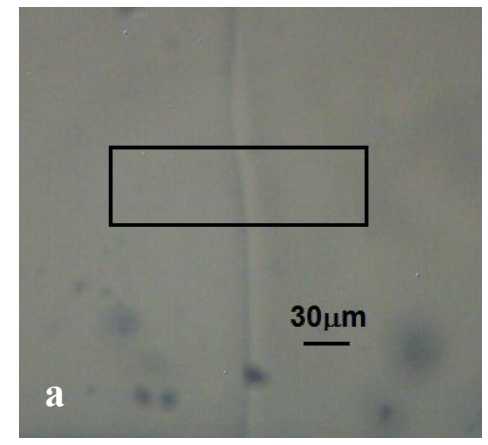

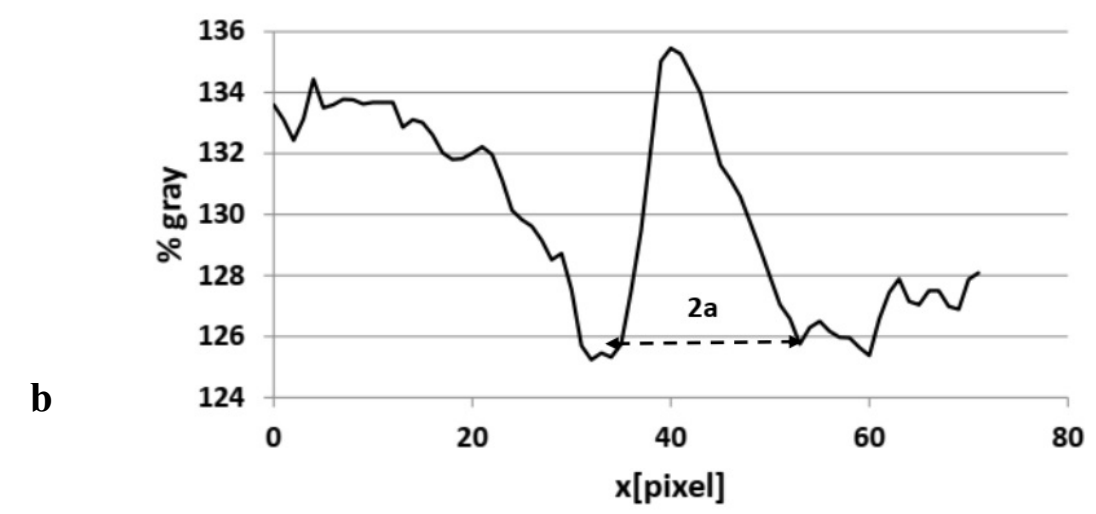

Fig. 3. a) Groove micrography after $50 \mathrm{~h}$; b) Grey tone intensity over the groove zone taken with ImajeJ $\AA$. 


\section{Results and Discussion}

Half-width $a_{e}$ as a function of time is shown in Fig. 4a. It can be seen that $a_{e}$ grows over time but its growth rate decreases. The curve given by $a_{e}$ follows equation (4):

$$
a_{e}(t)=a_{e 1}\left(\frac{t}{t_{1}}\right)^{\frac{1}{4}}
$$

where $a_{e 1}$ is the half-width observed at time $t_{1}$. We can see that the experimental data are better adjusted in the initial stage by equation 4 than in the final stage of the experiment. We also notice that the experimental data obtained from the grey profile have greater dispersion when the GB groove becomes wider. This dispersion is associated with the difficulty to determine the half-width at long times. There is a notable tendency to equation (4) by the initial experimental data, but the difficulty observed in determining the half-width at long times produces a visible dispersion at long times. To analyze the experimental data in a different way and verify that they have a similar behavior to the one described by equation (4), we plotted $\operatorname{Ln}\left(\frac{a_{e}}{a_{e_{0}}}\right)$ vs $\operatorname{Ln}\left(\frac{t}{t_{e 0}}\right)$ as shown in Fig. 4b. The behavior of the results was described by the linear relationship shown below:

$$
\operatorname{Ln}\left(\frac{a_{e}}{a_{e 0}}\right)=c \operatorname{Ln}\left(\frac{t}{t_{e 0}}\right)+b
$$

Eqn. 5

where $a_{e 0}$ and $t_{e 0}$ are the first measured pair of values. The parameter values are:

$$
b=(-0,51 \pm 0,09) \quad \text { y } c=(0,25 \pm 0,02)
$$

The adjustment has a regression coefficient $R^{2}=0.80276$. As it can be seen, the slope becomes indistinguishable for a value of 1/4. It agrees with what is observed in Fig. 4a. These results suggest that the association of the grey profile with the GB groove is reasonable and that the process by which the groove evolves could be surface selfdiffusion.

To complete the association, the value of parameter $B$ was identified in the linear adjustment, which appears in equation (1). Equation (5) was rewritten for this purpose:

$$
a_{e}=a_{e 0}\left(\frac{t}{t_{0}}\right)^{c} e^{b}
$$

Eqn. 6

Parameter $B$ is given by: $\quad B=\frac{1}{t_{0}}\left(a_{e 0} \frac{e^{b}}{2,3}\right)^{4}$

From the data, $\quad B=(1,2 \pm 0,5) 10^{-26} \mathrm{~m}^{4} \mathrm{~s}^{-1}$ was obtained.

With this value and using equation (3), a value for the surface self-diffusion coefficient $D_{S}=(3 \pm 1) 10^{-9} \mathrm{~m}^{2} \mathrm{~s}^{-1}$ was calculated using the physical parameters reported in the appendix. This value for $D_{s}$ is comparable to that reported by Nasello and Di Prinzio (2011), who used a very similar method. These authors determined the surface selfdiffusion coefficient by measuring $m$ and using the time in which the groove reached a width of approximately 10 equation (3). Although they do not register the evolution of the groove, they found a value of $2.110^{-9} \mathrm{~m}^{2} \mathrm{~s}^{-1}$. 

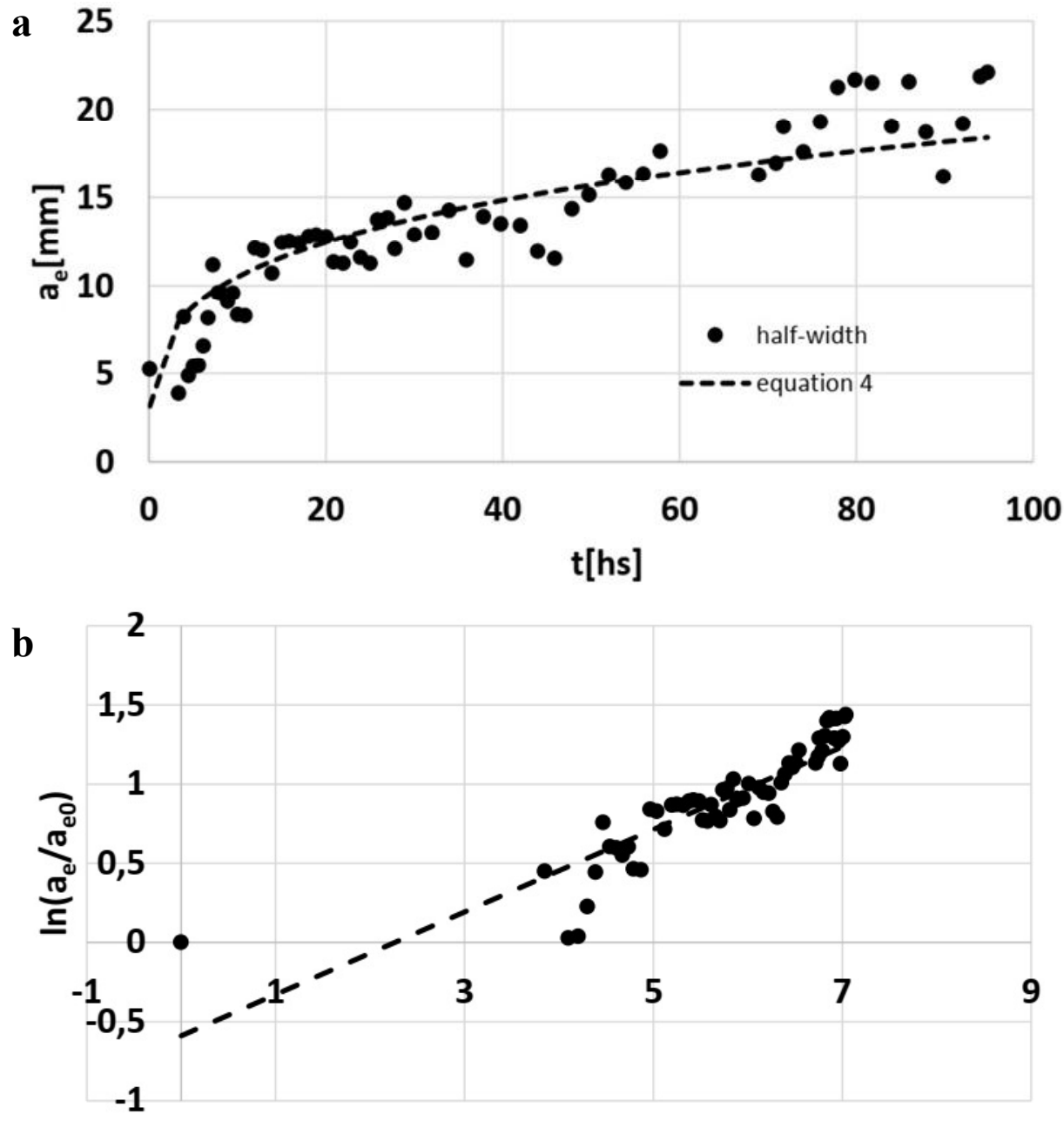

\section{$\ln \left(t / t_{e 0}\right)$}

Fig. 4. a) temporal evolution of the half-width $a_{e}$, the red line corresponds to the fitting given in equation (4); b) red line logarithmic fitting described in equation (5). Based on data reported in Stoler et al. 2019).

As it can also be seen, the value of transport coefficient $B$ is of the same order as that reported by Style and Woster (2005) It should be noted that they estimated the value considering the sample in contact with air and at a temperature of $-1{ }^{\circ} \mathrm{C}$. The value of $B$ obtained by Style and Woster (2005) at $\mathrm{T}=-1{ }^{\circ} \mathrm{C}$ was related to a solid- water-vapor interface. The authors present a Hamaker constant that was obtained from a theoretical paper by Wettlaufer and Worster (1995). However, in our experiment, the interface was ice-water-silicone oil. $\mathrm{Gu}$ (2001) measured experimentally the interface energy of water-silicone oil and the Hamaker constant corresponding 
to a glass-water-silicone oil interface. The Hamaker constant for our experiment is consistently similar to the experimental constant obtained by $\mathrm{Gu}$ (2001). In general, the physical parameters do not vary with temperature (Ambler et al. 2017, Hallett 1963), so the dependence of $B$ on temperature is as consequence of the explicit temperature dependence. We obtain $B=(1,2 \pm 0,5) 10^{-26} \mathrm{~m}^{4} \mathrm{~s}^{-1}$, if we use the interface energy and Hamaker constant by $\mathrm{Gu}$ (2001) and $\mathrm{T}=-5^{\circ} \mathrm{C}$. This value is similar to the value $B$ obtained in this experimental work.

In this paper, development of a new method to study the formation of the GB groove and identify the physical mechanism that produces it. Mullins (1957) determined that in the case that the sample suffered evaporation-condensation, the width behaves following an equation similar to equation (1) but with an exponent of $1 / 2$, and in another work (Mullins 1960), the same author determined that the exponent by volumetric diffusion (Style and Worster 2005) was $1 / 3$. Robertson (1981), presented the evolution of the width groove by different transport mechanisms and each one responded to a law similar to that given by equation (1) but with different exponents. In this work, the ice sample was placed in ultrapure silicone oil in order to avoid evaporation-condensation and the dominant transport mechanism was surface selfdiffusion. As it can be seen, the evolution of the groove width is consistent with the presence of a quasi-liquid layer at the silicon-ice interface. However, the sample can be studied in other physical conditions and thus be able to identify the transport process by simple exponent analysis. In our experiment, the bicrystal misorientation was not determined but we must clarify that the surface self-diffusion coefficient could depend on this variable. Therefore, the experimental method developed in this work would allow us to study the surface self-diffusion coefficient of ice at different temperatures (between $-2^{\circ} \mathrm{C}$ and $-15^{\circ} \mathrm{C}$ according to our experimental setup) with different conditions of impurities, and also with different surface crystalline planes.

\section{References}

Alley, R. B., Marotzke, J., Nordhaus, W. D., Overpeck, J. T., Peteet, D. M., Pielke, R. A. and WALlACE, J. M. (2003): Abrupt climate change. Science, 299(5615): 2005-2010.

Alley, R. B., Meese, D. A., Shuman, C. A., Gow, A. J., Taylor, K. C., Grootes, P. M., White, J. W. C., Ram, M., Waddington, E. D., Mayewski, P. A. and Zielinski, G. A. (1993): Abrupt increase in Greenland snow accumulation at the end of the Younger Dryas event. Nature, 362(6420): 527-529. doi: 10.1038/362527a0

Ambler, M., VorselaArs, B., Allen, M. P. and Quigley, D. (2017): Solid-liquid interfacial free energy of ice Ih, ice Ic, and ice 0 within a mono-atomic model of water via the capillary wave method. The Journal of Chemical Physics, 146(7): 074701.

azuma, N., Miyakoshi, T., Yokoyama, S. and Takata, M. (2012): Impeding effect of air bubbles on normal grain growth of ice. Journal of Structural Geology, 42: 184-193.

BARRIE, L. A. (1986): Arctic air chemistry: An overview. In: B. StonehoUse (ed.): Arctic Air Pollution, Cambridge Univ. Press, New York, pp. 5-23.

Brumberg, A., Hammonds, K., BaKer, I., Backus, E. H., Bisson, P. J., Bonn, M. and Shultz, M. J. (2017): Single-crystal Ih ice surfaces unveil connection between macroscopic and molecular structure. Proceedings of the National Academy of Sciences, 114(21): 5349-5354.

DiBB, J. E. (1992): The accumulation of ${ }^{210} \mathrm{~Pb}$ at Summit, Greenland since 1855. Tellus B, 44(1): 72-79.

DiBB, J. E., WhitLOW, S. I. (1996): Recent climate anomalies and their impact on snow chemistry at South Pole, 1987 - 1994. Geophysical Research Letters, 23(10): 1115-1118. 
DibB, J. E., JAFFREzo, J. L. and LegRAND, M. (1992): Initial findings of recent investigations of air-snow relationships in the Summit region of the Greenland Ice Sheet. Journal of Atmospheric Chemistry, 14(1-4): 167-180.

Durand, G., Weiss, J., Lipenkov, V., Barnola, J. M., Krinner, G., Parrenin, F. and Bigler, M. (2006): Effect of impurities on grain growth in cold ice sheets. Journal of Geophysical Research: Earth Surface, 111(No.F1): F01015. doi: 10.1029/2005JF000320

Faria, S. H., Weikusat, I. and Azuma, N. (2014): The microstructure of polar ice. Part I: Highlights from ice core research. Journal of Structural Geology, 61: 2-20.

Fegyveresi, J. M., Alley, R. B., Spencer, M. K., Fitzpatrick, J. J., Steig, E. J., White, J. W. C., MCCONNELl, J. R. and TAYLOR, K. C. (2011): Late-Holocene climate evolution at the WAIS Divide site, West Antarctica: bubble number-density estimates. Journal of Glaciology, 57(204): 629-638.

Fukazawa, H., MaE, S. (2000): The vibrational spectra of ice Ih and polar ice. In: Physics of Ice Core Records. Hokkaido University Press. pp. 25-42.

Gu, Y. (2001): Experimental determination of the Hamaker constants for solid-water-oil systems. Journal of Adhesion Science and Technology, 15(11): 1263-1283.

HalletT, J. (1963): The temperature dependence of the viscosity of supercooled water. Proceedings of the Physical Society, 82(6): 1046.

Hobis, P. (1974): Ice Physics, Oxford University Press. 837 p.

MulLINS, W.W. (1960): Grain boundary grooving by volume diffusion. Transactions of the American Institute of Mining and Metallurgical Engineers, 218 (2): 354-361.

Mullins, W.W. (1957): Theory of Thermal Grooving. Journal of Applied Physics, 28: 333-339.

Nasello O. B., Di Prinzio C. L. (2011): Anomalus effects of hydrostatic pressure on ice surface self-diffusion. Surface Science, 605: 1103-1105.

Nasello, O. B., Di Prinzio, C. L. and Guzmán, P. G. (2007): Grain boundary properties of ice doped with small concentrations of potassium chloride $(\mathrm{KCl})$. Journal of Physics: Condensed Matter, 19(24): 246218. doi: 10.1088/0953-8984/19/24/246218

Rempel, A. W., Waddington, E. D., Wettlaufer, J. S. and Worster, M. G. (2001): Possible displacement of the climate signal in ancient ice by premelting and anomalous diffusion. Nature, 411(6837): 568-571.

RoBertson, W. M. (1981): Thermal Etching and Grain Boundary Grooving Silicon Ceramics. Journal of the American Ceramic Society, 64(1): 9-13.

Stoler, D., Lado, M., Arcila, R. P., Varela, G. A. and Di Prinzio, C. L. (2019): Determinación del coeficiente de auto-difusión superficial del hielo Ih. Anales AFA, 30(1): 6-9.

Style, W., Worster, M. G. (2005): Surface transport in premelted films with application to grainboundary grooving. Physical Review Letters, 95: 176102. doi: 10.1103/PhysRevLett.95.176102

Wehinger, B., Chernyshov, D., Krisch, M., Bulat, S., Ezhov, V. and Bosak, A. (2014): Diffuse scattering in Ih ice. Journal of Physics: Condensed Matter, 26(26): 265401.

Weiss, J., Vidot, J., Gay, M., Arnaud, L., Duval, P. and Petit, J. R. (2002): Dome Concordia ice microstructure: impurities effect on grain growth. Annals of Glaciology, 35: 552-558.

Wettlaufer, J. S., Worster, M. G. (1995): Dynamics of premelted films: frost heave in a capillary. Physical Review E, 51(5): 4679.

\section{Appendix}

Experimental parameters for pure ice published by P. Hobbs (1974):

$$
\begin{aligned}
& \Omega=3.610^{-29} \mathrm{~m}^{3} \\
& \nu=3.2910^{18} 1 / \mathrm{m}^{2} \\
& \mathrm{k}=1.3810^{-23} \mathrm{~J} /{ }^{\circ} \mathrm{K} \\
& \gamma=10910^{-3} \mathrm{~J} / \mathrm{m}^{2}
\end{aligned}
$$

